\title{
BRANCH RETINAL VEIN OCCLUSION: DO WE REALLY NEED TO TREAT IN HASTE
}

\author{
Devendra Saxena ${ }^{1}$, Harsha C. Jani ${ }^{2}$
}

${ }^{1}$ Associate Professor, Department of Ophthalmology, Pramukhswami Medical College, Gujarat. 2 Professor and HOD, Department of Ophthalmology, Pramukhswami Medical College, Gujarat.

\section{ABSTRACT}

\section{BACKGROUND}

It is important to know the natural history of branch retinal vein occlusion in order to understand that any benefit attributed to intervention of any kind is due to the effect of the treatment alone and not due to natural course of the disease. In view of so many treatment options available, it becomes important to understand the natural outcome in case of BRVO, so one can decide when to intervene.

\section{AIMS}

1. To find out natural visual outcome in patients with recent onset BRVO.

2. To find out what percentage of patients develop complications in long term.

\section{METHODS AND MATERIALS}

20 patients seen in retina clinic with branch retinal vein occlusion of recent onset were included in the study from 2012 to 2014. Their best corrected visual acuity (BCVA), fundus photograph, intraocular pressure, and anterior segment findings were recorded. They were followed at 3 monthly interval for a period of one year.

\section{RESULTS}

Out of 20 patients with BRVO, 16 had involvement of superotemporal arcade and 4 had inferotemporal. 13 (65\%) patients had final visual acuity of more than 6/18 on Snellen chart and 7 (35\%) had visual acuity of less than 6/18. Out of 13 patients, 5 (25\%) patients had final visual acuity of 6/9-6/6.

\section{CONCLUSION}

It is advisable to follow up patients of BRVO with visual acuity of $6 / 18$ or better for a period of 6 months before undertaking any intervention and to intervene only if they show any deterioration on follow up in visual acuity or develop any complication secondary to BRVO.

\section{KEYWORDS}

Retinal Vein Occlusion, Natural Course, Macular Oedema.

HOW TO CITE THIS ARTICLE: Saxena D, Jani HC. Branch retinal vein occlusion: do we really need to treat in haste. J. Evolution Med. Dent. Sci. 2016;5(57):3926-3928, DOI: 10.14260/jemds/2016/898

\section{INTRODUCTION}

In the recent era of free availability of anti-VEGF (Vascular endothelial growth factors) and their inadvertent use in various kind of retinal vascular pathologies like vascular, inflammatory, autoimmune, or age-related warrants a balanced approach in dealing with use of these agents. (1)

Branch retinal vein occlusion has a good visual outcome as compared to CRVO (Central retinal vein occlusion), so inappropriate use of anti-VEGF should be avoided.

Natural history of the visual outcome can act as the basis to compare outcome of various treatment modalities for the disease. So, this study will help us to decide whether and when to intervene or else wait for the natural recovery.

This will help to prevent unnecessary treatment-related morbidity along with reduction in financial burden to the patient. $(2,3)$

Financial or Other, Competing Interest: None.

Submission 07-05-2016, Peer Review 16-06-2016,

Acceptance 23-06-2016, Published 16-07-2016.

Corresponding Author:

Dr. Devendra Saxena

Associate Professor,

Vitreo-Retinal Consultant,

Department of Ophthalmology,

PSMC, Karamsad-388325, Anand, Gujarat.

E-mail: deekaysaxena@yahoo.com

DOI: $10.14260 /$ jemds $/ 2016 / 898$

\section{METHODS}

20 patients of recent onset BRVO who were seen during period of 2012 to 2014 were taken into study and followed for a period of 1 year. Their visual acuity at time of presentation, fundus findings, intraocular pressure, anterior segment findings are recorded, and then followed 3 monthly for a period of one year.

\section{Inclusion Criteria}

1. Patients with definitive diagnosis of BRVO.

2. Patients who are seen with in a period of three months of onset of visual symptoms.

After 3 months, the visual symptoms might change due to decrease in retinal haemorrhage and macular oedema and would fail to provide any valid information about natural history of the disease.

\section{Exclusion Criteria}

1. Patients with associated retinal vascular disease.

2. Patients with diabetic retinopathy.

3. Patients with inflammation-induced vascular occlusion.

4. Patients with advanced glaucomatous optic disc damage.

5. Patients with macular pathology. 
Natural history was performed by recording BCVA on Snellen's chart for distance and near slit-lamp examination for iris neovascularisation and applanation tonometry for baseline intraocular pressure. Dilated fundus examination and fundus photographs were taken at the time of presentation. The above protocol was maintained on all follow up visits for a period of one year.

Fundus fluorescein angiography was done only when there was a suspicion of neovascularisation or there was a marked decrease in visual acuity from previous visit in the form of loss of 2 Snellen line to rule out macular ischaemia or macular oedema.

Descriptive statistics was computed for the demographic and clinical variables.

\section{RESULTS}

Out of 20 patients with BRVO $16(80 \%)$ had involvement of superotemporal arcade and $4(20 \%)$ had inferotemporal major arcade involvement. Superotemporal involvement is more because of more arteriovenous crossings in superior as compared to inferior arcade. $(4,5)$

More than $13(65 \%)$ patients had final vision of $6 / 18$ or better and 7 (35\%) had vision of less than 6/18 after one year of follow up. Out of 13 patients, 5 (38\%) patients had final vision of $6 / 9$ to $6 / 6$.

Visual acuity stabilised after a period of 6 months in most of the patients. $(6,7)$

Most common cause in decrease in visual acuity was cystoid changes at macula and macular ischaemia, which was confirmed by fundus fluorescein angiography. $(8,9)$

None of the patients in our series developed retinal neovascularisation or iris neovascularisation, which could be due to small sample size of the study and less incidence of neovascularisation in BRVO as compared to CRVO (Central retinal vein occlusion).(10)

BRVO was more common in men as compared to females (14 male and 6 females) i.e. ratio of 2.3:1 18 patients (90\%) were over $50 \mathrm{yrs}$. of age and $2(10 \%)$ were under 50.

\begin{tabular}{|c|c|c|c|c|c|}
\hline $\begin{array}{c}\text { Sl. } \\
\text { No. }\end{array}$ & $\begin{array}{c}\text { At } \\
\text { Presentation }\end{array}$ & $\mathbf{3}$ mth. & $\mathbf{6}$ mth. & $\mathbf{9}$ mth. & $\mathbf{1 2}$ mth. \\
\hline 1. & $6 / 9 \mathrm{P}$ & $6 / 9 \mathrm{P}$ & $6 / 9$ & $6 / 9$ & $6 / 9$ \\
\hline 2. & $6 / 18 \mathrm{P}$ & $6 / 12$ & $6 / 12$ & $6 / 9$ & $6 / 9$ \\
\hline 3. & $6 / 18$ & $6 / 18$ & $6 / 12 \mathrm{P}$ & $6 / 12 \mathrm{P}$ & $6 / 12 \mathrm{P}$ \\
\hline 4. & $6 / 18$ & $6 / 18$ & $6 / 18$ & $6 / 18$ & $6 / 18$ \\
\hline 5. & $6 / 36$ & $6 / 36$ & $6 / 36$ & $6 / 36$ & $6 / 36$ \\
\hline 6. & $6 / 36$ & $6 / 36$ & $6 / 18$ & $6 / 12$ & $6 / 6 \mathrm{P}$ \\
\hline 7. & $6 / 60$ & $6 / 60$ & $6 / 18$ & $6 / 18$ & $6 / 18$ \\
\hline 8. & $6 / 24$ & $6 / 18$ & $6 / 12 \mathrm{P}$ & $6 / 12$ & $6 / 12$ \\
\hline 9. & $6 / 18$ & $6 / 18$ & $6 / 18$ & $6 / 18$ & $6 / 18$ \\
\hline 10. & $6 / 60$ & $6 / 36$ & $6 / 36$ & $6 / 36$ & $6 / 36$ \\
\hline 11. & $6 / 24$ & $6 / 18$ & $6 / 12$ & $6 / 9$ & $6 / 6 \mathrm{P}$ \\
\hline 12. & $6 / 36$ & $6 / 36$ & $6 / 24$ & $6 / 24$ & $6 / 24$ \\
\hline 13. & $6 / 18$ & $6 / 18$ & $6 / 18$ & $6 / 18$ & $6 / 18$ \\
\hline 14. & $6 / 24$ & $6 / 24$ & $6 / 18$ & $6 / 18$ & $6 / 18$ \\
\hline 15. & $6 / 24$ & $6 / 18$ & $6 / 12$ & $6 / 12$ & $6 / 12$ \\
\hline 16. & $6 / 12 \mathrm{P}$ & $6 / 12$ & $6 / 12$ & $6 / 12$ & $6 / 12$ \\
\hline 17. & $6 / 6 \mathrm{P}$ & $6 / 6 \mathrm{P}$ & $6 / 6$ & $6 / 6$ & $6 / 6$ \\
\hline 18. & $6 / 18$ & $6 / 18$ & $6 / 24$ & $6 / 36$ & $6 / 36$ \\
\hline 19. & $6 / 18$ & $6 / 18$ & $6 / 12$ & $6 / 9$ & $6 / 9$ \\
\hline 20. & $6 / 12$ & $6 / 36$ & $6 / 36$ & $6 / 18$ & $6 / 18$ \\
\hline \multicolumn{5}{|c|}{ Table 1: Visual Acuity at Presentation and } \\
\hline \multicolumn{7}{|c|}{ on Follow Up for One Year } \\
\hline
\end{tabular}

\section{DISCUSSION}

The BRVO study was conducted in 1984. In it, 199 eligible eyes were included. Mean follow up for a period of 3.1 yrs. was done. It was found that gain of at least 2 lines of distant visual acuity was greater in treated eyes.

BRVO is seen in $6^{\text {th }}$ or $7^{\text {th }}$ decade of life. One study found prevalence of $0.2 \%$ in patients over 40 yrs. Prevalence increases to $0.5 \%$ after 65 yrs. of age.

An idiopathic thrombus at the site of arteriovenous crossing site (AVCS) typifies the presentation in nearly all BRVO. Non-AVCS BRVO are found in inflammatory or iatrogenic. At AV crossing, the artery and vein share a common adventitial sheath. This suggests the reason of thrombus formation. Some degree of thrombus recanalization eventually follows allowing partial drainage of retinal blood flow.

Long-term visual acuity outcome is generally reported as $6 / 12$ or better in $53 \%$ of patients, $6 / 18$ to $6 / 60$ in $28 \%$ and less than $6 / 60$ in $19 \%$.

In our study, $65 \%$ patients had visual acuity of $6 / 18$ or better and $35 \%$ less than $6 / 18$.

It emphasises that patients with BRVO can be followed safely for a period of 6 months by which time the visual acuity stabilises in most of the cases. Invasive investigations in the form of FFA should be undertaken after 6 months by which time most of the haemorrhages and exudates had cleared and any areas of macular ischaemia, capillary nonperfusion, or cystoid changes at macula can be clearly documented.

It is not necessary to treat all the patients at the time of presentation with intravitreal steroids or anti-vascular endothelial growth factor, because the effect of these medications is temporary. Moreover, VEGF act as stimulus for opening of shunt vessels beyond the level of block for reestablishing the circulation.(11) Early injection of anti-VEGF may help in reducing the macular oedema associated with BRVO, but simultaneously it may hinder eyes natural response to recover the block. That's why, we get more haemorrhages and infarcts once the effect of these agents wanes off.

It is better to wait for natural recovery to take place at least for a period of 6 months by which time most of the visual recovery is stabilised and then intervene based on FFA findings.

In this way, we save unnecessary treatment related morbidity to the patient and can utilise the available modalities of treatment in most rational way.

\section{REFERENCES}

1. Ramezani A, Entezari M, Moradian S, et al. Intravitreal triamcinolone for acute branch retinal vein occlusion: a randomised clinical trial. J Ophthalmic Vis Res 2011;6(2):101-8.

2. Hayreh SS. Ocular vascular occlusive disorders: natural history of visual outcome. Prog Retin Eye Res 2014;41:1-25.

3. Hayreh SS, Zimmerman MB. Branch retinal vein occlusion: natural history of visual outcome. JAMA Ophthalmol 2014;132(1):13-22.

4. Jonas J, Paques M, Mones J, et al. Retinal vein occlusions. Dev Ophthalmol 2010;47:111-35. 
5. Rogers SL, McIntosh RL, Lim L, et al. Natural history of branch retinal vein occlusion: an evidence-based systematic review. Ophthalmology 2010;117(6):1094101, e5.

6. Ehlers JP, Fekrat S. Retinal vein occlusion: beyond the acute event. Surv Ophthalmol 2011;56(4):281-99.

7. Shroff D, Mehta DK, Arora R, et al. Natural history of macular status in recent onset branch retinal vein occlusion: an optical coherence tomography study. Int. Ophthalmol 2008;28(4):261-8.

8. Margolis R, Singh RP, Kaiser PK. Branch retinal vein occlusion: clinical findings, natural history, and management. Review Erratum in: Compr Ophthalmol Update 2007;8(1):50.
9. Finkelstein D. Ischaemic macular oedema. Recognition and favourable natural history in branch vein occlusion. Arch Ophthalmol 1992;110(10):1427-34.

10. Hayreh SS, Rojas P, Podhajsky P, et al. Ocular neovascularization with retinal vascular occlusion-III. Incidence of ocular neovascularization with retinal vein occlusion. Ophthalmology 1983;90(5):488-506.

11. Pieris SJ, Hill DW. Collateral vessels in branch retinal vein occlusion. Trans Ophthalmol Soc UK 1982;102(Pt1):178-81. 